\title{
Organizational safety climate and workplace violence among primary healthcare workers in Malaysia
}

\author{
Sudeash Rajakrishnan, Victor Hoe Chee Wai Abdullah, Nasrin Aghamohammadi \\ Department of Social and Preventive Medicine, Faculty of Medicine, University of Malaya, Kuala Lumpur, Malaysia
}

\begin{abstract}
Article Info
Article history:

Received Mar 8, 2021

Revised Nov 8, 2021

Accepted Nov 25, 2021

Keywords:

Healthcare workers

Organizational safety climate

Primary healthcare

Workplace violence

ABSTRACT

Workplace violence (WPV) has become a global safety and health concern in recent times particularly in the healthcare sector. In addition, low levels of organisational safety climate (OSC) have been associated with higher occurrence of occupational related health outcomes. Hence, the objective of this study was to determine the association between organisational safety climate and workplace violence among government primary healthcare workers. A cross-sectional study among a stratified random sample of 838 primary healthcare workers $(\mathrm{HCW})$ from the nine district health offices under the Selangor state health department. Two standardized selfadministered questionnaires were used to obtain data on WPV and OSC. Logistic regression models used to estimate the association between OSC and WPV. Prevalence of WPV was $68.5 \%$ whereby verbal abuse was the most common type $(65 \%)$ followed by bullying $(27 \%)$, physical violence $(6 \%)$ and sexual harassment (2\%). Nurses $(29.7 \%)$ were the most affected by WPV. The main perpetrators were relatives of patients (38\%). Low level of OSC was also associated with WPV $(\mathrm{OR}=3.04,95 \% \mathrm{CI}=1.45-6.41)$. The results of this study confirmed that safety climate is associated with WPV. Hence, interventions and efforts to prevent WPV among HCW should also include improving organizational safety factors.
\end{abstract}

This is an open access article under the $\underline{C C B Y-S A}$ license.

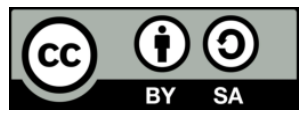

\section{Corresponding Author:}

Sudeash Rajakrishnan

Department of Social and Preventive Medicine, Faculty of Medicine, University of Malaya

Kuala Lumpur, Malaysia

Email: sudeash27@gmail.com

\section{INTRODUCTION}

Workplace violence (WPV) is defined as incidents where persons are abused, threatened or assaulted in circumstances related to their work, including commuting to and from work, involving explicit or implicit challenges to their safety, well-being or health [1], [2]. WPV is broadly categorized into two, i.e., physical (Slapping, pinching and Punching and psychological violence. Psychological violence can further be classified into verbal abuse, bullying and harassments (racial and sexual) [3]. WPV can also be classified based on the preparators. Type 1 is violence with criminal intent such as robbery, homicide. Type 2 is violence caused by clients, in these instance patients and their relatives. Type 3 is being violenced among colleagues and superiors. Type 4 is being personal relationship violenced spilling over to workplace [4]. WPV has become a global safety and health concern in recent times particularly in the healthcare sector globally as well as regionally [5]-[7]. Healthcare workers (HCW) include physicians, nurses, medical assistants, allied medical workers, public health workers, laboratory technicians, pharmacists, and administrative staff [8]. A study on workplace violence among Hospital Universiti Kebangsaan Malaysia (HUKM) nurses in 2011 reported that one nurse is exposed to workplace violence every other day [9] and a more recent study in 2018 reports a WPV prevalence of $71.3 \%$ among HCW in Hospital Kuala Lumpur 
(HKL) HCW's [10]. The most common type of violence faced by HCW is verbal abuse [11], [12]. On the other hand, in terms of location, the highest numbers of workplace violence incidences are seen in accident and emergency departments, psychiatric wards and intensive care unit [13]. The most vulnerable group of HCW are nurses, as the reported percentage of nurses being abused in psychiatric wards and accident and emergency departments is an astonishing $98 \%$ and $100 \%$ [11], [12] respectively and most of this violence are perpetrated by patients and their relatives.

Research suggests that WPV in general is significantly underreported, especially when there is no physical injury [14]. Reasons for underreporting of WPV among HCW include lack of a reporting policy, lack of faith in the reporting system, and fear of retaliation by superiors [15]. However, a growing body of research has identified that WPV from both patients and colleagues are significantly associated with psychological ill-health that is associated with high levels of anxiety, fear, post-traumatic stress disorder (PTSD), depression, and decreased work satisfaction [4]. Besides affecting an individual, WPV also affects an organization via increased absenteeism, lower productivity, and frequent litigation [16].

An extensive review of existing literature showed that studies concerning WPV have primarily focused on individual factors, under the hypothesis that occurrence of violence is generally determined by personal characteristics [17]. Hence, there is an increased need for a multidimensional approach to WPV related research [4], [18]. The International Labour Organization (ILO) guidelines for developing comprehensive WPV prevention measures propose this strategy, which includes individual training and counselling as well as improvements in safety and health-related organisational culture as well as policy [19]. Despite the fact that organisational issues such as understaffing, inadequate supervisor support, poor workgroup relationships, and job overload have been linked to increased workplace violence, more research on organisational safety factors is still highly required [4]. One of the main organizational factor affecting health and safety related outcomes in the healthcare environment is safety climate - the shared assessments of safety policies, procedures, and practices, and the perceptions and expectations workers have of workplace safety [20]. The concept of OSC encompasses the following: management and organizational practices (adequacy of training, provision of safety equipment, quality of safety management system) management values (management concern for employee well-being), employee involvement in workplace health and safety as well as employer employee communication on of safety and health [21]. The presence of high safety climate levels as been linked to a reduction in occupationally related health hazards [22].

Hence, the objective of this study to estimate the prevalence of WPV in relation to sociodemographic characteristic, job characteristics and OSC risk factors among primary healthcare workers.

\section{METHOD}

\subsection{Study design, study location and sampling}

This was a cross-sectional study conducted among HCW at government primary healthcare facilities in the state of Selangor, Malaysia. Selangor has a population of 6.53 million and is the most populated state in Malaysia. The government primary healthcare facilities located in the nine districts in Selangor receives the highest patient visit in Malaysia. Study participants were selected from the nine districts in Selangor via proportionate stratified random sampling method. The inclusion criteria were Malaysian citizen, aged between 21 and 60 years old. Besides that, participants must have had at least one year of working experience in one of the government district health facilities in Selangor. Contract workers, part-time workers and attachment students were excluded. In addition, participants were also randomly selected from the employee list provided by the district health departments using SPSS Statistics software Edition 24.

To ensure an adequate sample size and power of the study, the confidence interval (CI) was set at $95 \%$, an alpha $(\alpha)$ of $5 \%$ and $80 \%$ power of study. Hence, sample size was determined by two means, one by using population surveys in similar previous studies and using the measure of association [1], [2]. Based on the sample size calculation above, the largest sample size required for this study is 530. Given an estimated 53$91 \%$ response rate [1]-[3], a minimum of $1,000[(100 \div 53) \times 530=1,000]$ questionnaires were distributed. This study adhered to the Helsinki Declarations [23] which requires a protocol explaining the study's goals, data collection techniques, data uses, and participant privacy guarantees to be sent to the MOH's Medical Research and Ethical Committee.

\subsection{Instrumentation and data collection}

Two standardized self-administered questionnaires were used to obtain data on WPV (WHO-ILO) [24] and OSC (NOSACQ-50) [25]. The first questionnaire (WHO-ILO) had two parts to it eliciting information on: i) socio-demographic and work characteristic, and ii) workplace violence (WPV). The second questionnaire was the Nordic occupational safety climate questionnaire (NOSACQ-50) elicited information on Organisational Safety climate (OSC). The first part of WHO-ILO questionnaire on WPV among HCW elicited socio-demographic details of study participants which includes their gender, age, race 
and marital status. In terms of work characteristics, experience in years, profession, district health office, participation in shift work, interaction with patients, number of staffs present during a normal working day were determined. The second part of the questionnaire elicited data to determine the one-year prevalence of WPV. There were 32 questions in total covering two sections which covered data on physical violence and psychosocial violence (verbal abuse, mobbing/bullying, sexual harassment). Each section consisted eight questions on the types of violence experienced by the participants over the past 12-months, was it considered a typical incident by the respondents, the source of the violent act (the perpetrator), the location of the incident, was in preventable in, and respondents 'immediate respond to the incident, was there a formal report made to the organization and if not, why wasn't a report made. The questionnaire's reliability has been measured using a Cronbach Alpha Coefficient with the value of 0.83 [26].

The NOSACQ-50 was used to elicit information on workers' perceptions of management and workgroup safety related policies, procedures and practices at their individual workplace. The questionnaire contains seven safety climate dimensions, and has a total of 50 items: i) Management safety commitment and ability (nine items), ii) Management safety empowerment (seven items), iii) Management safety justice (six items), iv) Employees' commitment to safety (six items), v) Employees' safety priority and absence of risk acceptance (seven items), vi) Learning, communication and trust (eight items), vii) Trust in efficacy of safety systems (seven items). Respondents were asked to rate how strongly they agreed with each statement through a scale from 1 (strongly disagree) to 4 (strongly agree). Each dimension contained alternating positive and negative themed items to reduce acquiescent bias and extreme response bias. The score of each of these items was dichotomized by mean score points to determine scores obtained from respondents were high or low as recommended by the NOSACQ-50 developers. A mean score of <3.0 is categorized as low meanwhile a score of $\geq 3.0$ is categorized as high safety climate [26]. The questionnaire's reliability has been measured using a Cronbach Alpha Coefficient with the value of 0.87 [26].

A pilot study was conducted among $42 \mathrm{HCW}$ prior to distribution of the questionnaire. The data collected from the pilot study were first reviewed to determine the reliability of the questionnaire, upon which the questionnaire was then modified accordingly. An expert panel was asked to validate the content of the questionnaire. The questionnaires were distributed personally by the researcher together written informed consent. Each respondent was given a dedicated 45 minutes slot to complete the questionnaire during their annual healthcare safety course. Data for this study was collected within four weeks. In addition, all collected data is also kept private and confidential.

\subsection{Statistical analyses}

IBM SPSS Statistic Version 24 was used to manage and analyse the data. The raw data was checked for completeness, and all continuous data was subjected to a normality test. Normality testing revealed that all variables, including age and years of experience, were not distributed normally. Descriptive statistics were used to summarise respondents' socio-demographic and job characteristics, as well as OSC variables. For each form of WPV, the frequency and percentage were computed. The relationships of socio-demographic, occupational, and OSC variables with WPV were investigated using Chi-square statistics. Variables which had a p-value of less than 0.25 in a univariate analysis were included into the multivariate analyses as per Hosmer and Lemenshow's recommendation. Logistic regression was used to measure adjusted association between the independent variable and WPV. Significance level was set to be at $\mathrm{p}<0.05$.

\subsection{Ethical approval}

Ethical approval was granted by the University Malaya Medical Centre Research Ethics Committee (UMREC) and medical research and ethics committee (MREC) of the MOH. Each respondent was informed about the purpose of the study and also that all data obtained from them were kept confidential by using codes instead of any personal identifiers. This was a self-funded study.

\section{RESULTS AND DISCUSSION}

The total numbers of study participants were 838 giving a response rate of $83.8 \%$. The sociodemographic characteristics of the respondents are depicted in Table 1. Majority of the respondents were females (64\%), aged less than $30(50.6 \%)$, and married (56.9\%). Malays were the major ethnic group $(71.5 \%)$ followed by Indians at $14 \%$. In the context of work characteristics, $34.2 \%$ were nurses, $21.8 \%$ doctors, and $6.4 \%$ midwives.

The HCW's involved in this study were predominantly from health facilities in larger District health offices (DHO) $(65.8 \%)$ in comparison to facilities from small DHO (34.2\%). In terms of working experience, $64.8 \%$ of them had worked for less than 10 years. None of the respondents indicated were working shifts. Around $88 \%$ of the respondents indicated that their work involves interacting with patients. Most of the respondents indicated that they work with less than five workers $(55.6 \%)$ during most $(>50 \%)$ of their 
working hours. In terms of weather the respondents are worried of violence at their workplace, nearly half of (48.7) indicated they were very worried, $20.7 \%$ were extremely worried and only $18.7 \%$ were not worried at all. In this section, it is explained the results of research and at the same time is given the comprehensive discussion. Results can be presented in figures, graphs, tables and others that make the reader understand easily [14], [15]. The discussion can be made in several sub-sections.

Table 1. The distribution of socio-demographic characteristics ( $\mathrm{n}=838$ )

\begin{tabular}{|c|c|}
\hline Variable & $\begin{array}{c}\text { Sample data }(\mathrm{n}=838) \\
\text { Total }(\%)\end{array}$ \\
\hline \multicolumn{2}{|l|}{ Gender } \\
\hline Male & $302(36.0)$ \\
\hline Female & $536(64.0)$ \\
\hline \multicolumn{2}{|c|}{ Age (Range: $21-56$ years old) } \\
\hline$<29$ & $424(50.6)$ \\
\hline $30-39$ & $285(34.0)$ \\
\hline $40-49$ & $105(12.5)$ \\
\hline$>50$ & $24(2.9)$ \\
\hline \multicolumn{2}{|l|}{ Marital status } \\
\hline Single & $331(39.5)$ \\
\hline Married & 477 (56.9) \\
\hline Divorced & $22(2.6)$ \\
\hline Widow(er) & $8(1.0)$ \\
\hline \multicolumn{2}{|l|}{ Profession } \\
\hline Doctor & $183(21.8)$ \\
\hline Nurse & $287(34.2)$ \\
\hline Midwife & $54(6.4)$ \\
\hline Pharmacist & $36(4.3)$ \\
\hline Administrative & $36(4.3)$ \\
\hline Professional allied* & $23(2.7)$ \\
\hline Technical* & $42(5.0)$ \\
\hline Enforcement & $58(6.9)$ \\
\hline Fogging unit & $38(4.5)$ \\
\hline Support staff* & $53(6.3)$ \\
\hline Paramedics & $28(3.3)$ \\
\hline \multicolumn{2}{|l|}{ Ethnicity } \\
\hline Malay & $599(71.5)$ \\
\hline Chinese & $95(11.3)$ \\
\hline Indian & $117(14.0)$ \\
\hline Others & $27(3.2)$ \\
\hline \multicolumn{2}{|l|}{ District health office (DHO) } \\
\hline Small districts* & $287(34.2)$ \\
\hline Large districts* & $551(65.8)$ \\
\hline \multicolumn{2}{|c|}{ Working experience (Range: 1-32 years) } \\
\hline $1-10$ & $543(64.8)$ \\
\hline $11-20$ & $203(24.2)$ \\
\hline $21-30$ & $78(9.3)$ \\
\hline $31-40$ & $14(1.7)$ \\
\hline \multicolumn{2}{|l|}{ Shift work } \\
\hline Yes & $0(0.0)$ \\
\hline No & $838(100)$ \\
\hline \multicolumn{2}{|l|}{ Interaction with patients } \\
\hline Yes & $744(88.8)$ \\
\hline No & $94(11.2)$ \\
\hline \multicolumn{2}{|c|}{ Staff present during $(>50 \%)$ of work } \\
\hline $1-5$ & $466(55.6)$ \\
\hline $6-10$ & $253(30.2)$ \\
\hline $11-15$ & $70(8.4)$ \\
\hline \multicolumn{2}{|c|}{ Worried of violence at workplace } \\
\hline Not worried at all & $151(18.0)$ \\
\hline A little worried & $47(5.6)$ \\
\hline Worried & $58(6.9)$ \\
\hline Very worried & $408(48.7)$ \\
\hline Extremely worried & $174(20.8)$ \\
\hline
\end{tabular}




\subsection{Prevalence of workplace violence (WPV)}

Overall, $574(68.5 \%)$ of the 838 participants said they had been exposed to at least one of the four categories of violence; verbal abuse was the most common (65\%), followed by bullying/mobbing (27\%), physical violence $(6.0 \%)$, and the least common type was sexual harassment $(2 \%)$. Nurses $(44.8 \%)$ were the highest category to report WPV, followed by doctors $(15.1 \%)$, enforcement officers $(7.3 \%)$, and technical $(5.9 \%)$ and support $(5.2 \%)$ staffs. The remaining professions recorded prevalence of $<5.0 \%$. Lastly, highest prevalence of WPV in the past 12-months were among HCW working in larger districts (77.7\%) compared to smaller districts $(22.3 \%)$.

\subsection{Perpetrators of workplace violence}

Patients, relatives of patients/visitors, colleagues, superior/management, public and others were the six groups of perpetrators assessed in this study. Physical violence mostly executed by patients themselves (50\%) followed by public (47\%) and relatives of patients/visitors (12\%). In the case of verbal abuse, relatives of patients/visitors $(46 \%)$ were the most common preparators, followed by patients $(41 \%)$, colleagues $(9 \%)$, superiors $(2 \%)$ and public $(2 \%)$. In cases of bullying/mobbing, superiors $(65 \%)$ were the most common perpetrators, followed by relatives of patients/visitors (24\%) and patients themselves (10\%). Sexual harassment was mostly perpetrated by colleagues (33\%), patients $(28 \%)$ and superiors $(22 \%)$.

\subsection{Organizational safety climate (OSC) factors}

Total mean score for OSC was 2.96. The OSC was categorized based on the mean score low OSC $(<3.0)$ and high OSC ( $\geq 3.0), 54.9 \%$ reported low OSC and $45.1 \%$ reported high OSC. Managements' safety empowerment received the lowest mean score of 2.81 with $81 \%$ of the respondents scoring <3.0. On the other hand, Worker's safety priority and non-risk acceptance had the highest mean score of 3.10 with $66.9 \%$ of HCW having high OCS as shown in Table 2.

\begin{tabular}{|c|c|c|c|}
\hline Organisational safety climate (OSC) dimensions & $\mathrm{n}(\%)$ & Mean (SD) & Min-Max \\
\hline \multicolumn{4}{|l|}{ Management's safety priority and ability } \\
\hline Low & $592(70.6)$ & $2.83(0.38)$ & $2.00-3.32$ \\
\hline High & $246(29.4)$ & & \\
\hline \multicolumn{4}{|l|}{ Management's safety empowerment } \\
\hline Low & $679(81.0)$ & $2.81(0.23)$ & $2.29-3.34$ \\
\hline High & $159(19.0)$ & & \\
\hline \multicolumn{4}{|l|}{ Management's safety justice } \\
\hline High & $573(68.4)$ & $2.85(0.22)$ & $2.17-3.30$ \\
\hline Low & $265(31.6)$ & & \\
\hline \multicolumn{4}{|l|}{ Workers safety commitment } \\
\hline Low & $153(18.3)$ & $3.05(0.24)$ & $2.17-3.33$ \\
\hline High & $685(81.7)$ & & \\
\hline \multicolumn{4}{|l|}{ Workers safety priority and non-risk acceptance } \\
\hline Low & $277(33.1)$ & $3.10(0.36)$ & $2.43-3.86$ \\
\hline High & $561(66.9)$ & & \\
\hline \multicolumn{4}{|l|}{ Peer safety communication, learning and trust } \\
\hline Low & $358(42.7)$ & $3.00(0.18)$ & 2.63-3.71 \\
\hline High & $480(57.3)$ & & \\
\hline \multicolumn{4}{|l|}{ Workers' trust in efficacy of safety systems } \\
\hline Low & $372(44.4)$ & $3.07(0.38)$ & $2.00-3.71$ \\
\hline High & $466(55.6)$ & & \\
\hline \multicolumn{4}{|l|}{ Organizational safety climate (Total score) } \\
\hline Low & $460(54.9)$ & $2.96(0.20)$ & 2.49-3.86 \\
\hline High & $378(45.1)$ & & \\
\hline
\end{tabular}

\subsection{Association between socio-demographic characteristics, work characteristics and OSC dimensions with WPV}

Chi-square statistics were applied to measure the association between the three independent study variables; socio-demographic characteristics, work characteristics, and OSC dimensions with WPV. The observed p-value indicated the strength of association between the independent variables and the dependents variable. In terms of socio-demographic characteristics, gender, age, ethnicity, and marital status were all significantly $(\mathrm{p}<0.001)$ associated with WPV. The odds of females reporting exposure to WPV was higher than males. Similarly, the odds Chinese HCW reporting exposure to WPV was 5.7 times of a Malay HCW. Those HCW in the 30-39 age group and divorcees also had higher odds of reporting exposure to WPV compared to younger age group and single workers. As of work characteristics size of DHO, number of staff present during working hours and respondents feeling worried of violence were significantly $(p<0.001)$ associated with WPV.

Int J Public Health Sci, Vol. 11, No. 1, March 2022: 88-97 
There were no significant association found between different groups of workers, working experience and weather the respondents interact with patients or not $(\mathrm{p}>0.05)$ with reporting exposure to WPV.

The results demonstrated that larger districts have higher prevalence of WPV compared to smaller districts. In terms number of staffs present during working hours, those who worked with $\leq 10$ staffs had higher odds of reporting exposure to WPV. In addition, those HCW who are more worried of violence at work have lesser odds reporting exposure to WPV. In terms of OSC dimensions, results showed that respondents reporting exposure to WPV has a low score in all seven categories including total safety climate of OSC.

After simultaneous multivariate adjustment, when compared to males' females had higher prevalence of WPV Those in the age group of 30-39 and 40-49 reported a higher prevalence of WPV compared to those from age group of <30. Post adjustment, being married became a non-significant factor of WPV, however those HCW whom are divorced (or are widows(er)) reported higher prevalence compared to single HCW's. In terms of ethnicity, being Chinese reported a higher prevalence of WPV compared to Malay HCW's. In terms of work characteristics, those HCW's working in larger and those working with less than 10 co-workers for more than $50 \%$ of their working hours reported higher prevalence of WPV. In addition, those HCW the odds of exposure to WPV among those HCW whom reported of being extremely worried of WPV were 0.32 compared to those whom were not worried at all. Finally, a low level of safety climate was significantly associated with WPV among HCW in primary healthcare as presented in Table 3.

Table 3. The crude and adjusted association between socio-demographic characteristics, work characteristics, and organizational safety climate (OSC) dimensions with workplace violence (WPV) $(n=838)$

\begin{tabular}{|c|c|c|}
\hline Risk factors & Crude OR (95\% CI) & Adjusted OR (95\% CI) \\
\hline \multicolumn{3}{|l|}{ Gender } \\
\hline Male* & 1.00 & 1.0 \\
\hline Female & $2.95(2.19-3.98)$ & $5.44(3.53-8.39)$ \\
\hline \multicolumn{3}{|l|}{ Age (Range: 21-56 years old) } \\
\hline$<30^{*}$ & 1.00 & 1.0 \\
\hline $30-39$ & $2.69(1.95-3.71)$ & $3.86(2.21-6.77)$ \\
\hline $40-49$ & $2.16(1.38-3.38)$ & $3.58(1.67-7.66)$ \\
\hline$\geq 50$ & $0.62(0.21-1.87)$ & $0.34(0.79-1.45)$ \\
\hline \multicolumn{3}{|l|}{ Marital status } \\
\hline Single* & 1.0 & 1.0 \\
\hline Married & $1.67(1.23-2.27)$ & $1.20(0.70-2.05)$ \\
\hline Divorced & $4.05(1.67-9.81)$ & $4.13(1.22-7.90)$ \\
\hline Widow(er) & $2.85(0.68-11.46)$ & $7.54(2.13-13.83)$ \\
\hline \multicolumn{3}{|l|}{ Ethnicity } \\
\hline Malay* & 1.0 & 1.0 \\
\hline Chinese & $5.70(3.56-9.13)$ & $7.31(3.58-14.89)$ \\
\hline Indian & $1.35(0.89-2.05)$ & $0.41(0.23-0.72)$ \\
\hline Others & $0.44(0.15-1.28)$ & $0.74(0.18-3.08)$ \\
\hline \multicolumn{3}{|l|}{ Pejabat Kesihatan Daerah (PKD) } \\
\hline Small PKD* & 1.0 & 1.0 \\
\hline Large PKD & $4.77(3.50-6.50)$ & $4.31(2.66-7.00)$ \\
\hline \multicolumn{3}{|c|}{ Staff present during $(>50 \%)$ of work } \\
\hline$>11^{*}$ & 1.0 & 1.0 \\
\hline$<10$ & 3.53 & $3.04(1.45-6.41)$ \\
\hline \multicolumn{3}{|l|}{ Worried of Violence } \\
\hline Not worried at all* & 1.00 & 1.0 \\
\hline A little worried & $0.61(0.31-1.20)$ & $1.03(0.43-2.63)$ \\
\hline Worried & $0.52(0.27-0.97)$ & $0.73(0.29-1.85)$ \\
\hline Very worried & $0.51(0.35-0.75)$ & $1.82(1.00-3.16)$ \\
\hline Extremely worried & $0.20(0.12-0.33)$ & $0.32(0.16-0.61)$ \\
\hline \multicolumn{3}{|c|}{ Organisational safety climate (OSC) dimensions } \\
\hline Safety climate total score & & \\
\hline High* & 1.0 & 1.0 \\
\hline Low & $5.45(3.98-7.47)$ & $3.02(1.81-5.01)$ \\
\hline
\end{tabular}

\subsection{Discussion}

Over one third of the HCW's surveyed in the scope of this study reported of being exposed to at least one of four types WPV in the past one year. The one-year prevalence of WPV among primary HCW in Selangor was $68.5 \%$ indicating that 574 out of 838 were victims of WPV. However these findings were significantly lower than the prevalence reported in a recent study of WPV among HCW in Hospital Kuala Lumpur in 2017 which reported a prevalence of $71.3 \%$ [10] as well as 90\% in Saudi Arabia [27]. In contrary, the observed prevalence in this study was higher than those in found in the study among HCW in HUKM (3.7\%) [9], in Jordan (65.5\%) [28], China (56.4\%) [29], and in Saudi Arabia (28\%) [30]. The lower 
prevalence between this study compared to the study in HKL [31] is because the later was among accident and emergency HCW's in the principle tertiary hospital in Malaysia located at the heart of the densely populated Kuala Lumpur and these factors were identified previously to be significant in predicting workplace violence [32]. In comparison to the HUKM study which observed a significantly lower prevalence, it is because that study only measured three months prevalence of WPV using a different study instrument in contrary to the present study which measured one-year prevalence.

The most common type WPV observed in this study was verbal abuse (65\%), followed by bullying (27\%), next was physical violence (6\%) and the least common being sexual harassment (2\%). These results are similar with multiple other studies [33], [34]. Verbal abuse is usually reported far more common than others because it is known to precede subsequent physical violence and bullying. The most common perpetrators of WPV were relatives followed by patients, colleagues, superiors and public. This is consistent with the study done in HKL as well [10].

The prevalence of workplace violence was higher in health care facilities in larger districts $(65.8 \%)$ compared to smaller districts $(34.2 \%)$. Majority of violent incidents occur inside the health facility compared to outside (home visiting, commuting to and from work). This is due to the bigger workforce in bigger districts as well as the density of patients and patient load at the facilities [10]. Multiple logistic regressions controlling for confounders found that odds females have a higher 5.5 times odds of reporting exposure to WPV compared to males. This finding is similar to other studies [34]-[36] although multiple other studies do report no difference in the prevalence between males and females [9], [10]. Most studies report that the lower the age the higher the odds of experiencing WPV [10], however, this study it was noted the middle-aged group of 31-50 had higher odds compared to the younger HCW. This proves that all age group are equally at risk of WPV in-terms of primary healthcare setting. The other significant factors were race and marital status, odds were higher among Chinese compared to Malays and being Indian was a protective factor. Besides divorcees and widows also had higher odds compared to single HCW.

In terms of work-related factors, the significant factors which increase the odds of experiencing WPV after adjustment were working in larger district facilities as well as working with $\leq 10 \mathrm{HCW}$ during a normal working hour. Profession was not significant although the prevalence was high among nurses. In the United States, long waiting hours, not satisfied with treatment, understaffing and poor waiting areas and treatment rooms were identified as risk factors of WPV among HCW [37]. Similarly, in Malaysia WPV is explained by long waiting period of more than 20 minutes, refusal of referral to tertiary centres, persistent and untreated pain, patients' anxiety and misunderstandings due to language barrier or in view of difference in tradition, or unconducive work environment [10].

Finally, in terms of OSC, a low level of safety climate was strongly associated with higher prevalence of all sources of verbal abuse. While differences in the assessment of safety climate may exist, the findings in this study are consistent with previous evidences showing a strong link between safety climate factors and work-related injuries [38] and physical and psychological job abuse [39]. In a study of organizational determinants of safety climate in nursing homes, a more positive safety climate reduced number of workplace errors which lead to a violent event [40]. This provides some support for the fact that OSC were significant inverse determinants of WPV in the current study. Besides findings of this study is also in line with previous research in a psychiatric setting by Isak et al. where employee positive perceptions of management's commitment to safety were significantly associated with fewer patient perpetrated aggressive incidents [41]. In addition, their study was done in a very high-risk environment where likelihood of a violent incident occurring is high. Positive climate ratings for violence prevention indicated a lower risk of being exposed to violence over the course of six months in longitudinal research. However, the tool utilised to measure OSC in this study differed from the current study. Furthermore, that study $(n=176)$ only included nurses [42]. Although individual factors of OSC were not significant after controlling for confounders, this study does show that HCW working in a low OSC environment have five times more odds of being exposed to WPV.

This study contains some limitation, recall bias is one of the main limitations as WPV was measured utilising a retrospectively self-administered questionnaire. There was no official data registry on WPV among primary HCW in Selangor at the time this study was conducted. As a result, self-reporting was the only viable option for obtaining information on WPV. The study's questions asked whether or not workers had been exposed to WPV. This simple question was chosen because there is no agreed-upon definition of what constitutes WPV, and it's possible that different people will interpret it differently. Although all participants were given standard operational definitions of WPV, the concept of WPV and its definitions may vary depending on the individual as well as situational factors [43]. Given these limitations, our approach was based on the assumption that if the worker reported having experienced WPV, it must have been so. Besides, the cross-sectional nature of the survey limits the capability of this study to establish causality. In addition, the questionnaire on WPV was not originally developed to specifically determine the associations of OSC and WPV. It represents an exploratory analysis and must be interpreted as such. On the whole, since OSC represents

Int J Public Health Sci, Vol. 11, No. 1, March 2022: 88-97 
a global assessment on the general state of workplace safety, the findings in this study are also conceptually sound. Besides, the participants of this study were randomly selected using a proportional random sampling method hence improving the generalizability of findings to primary healthcare workers in Selangor, and perhaps Malaysia. In addition, to the knowledge of the researchers, it represents the first formal evaluation of WPV in the primary health sector in Malaysia, and the first evaluating the association between OSC and WPV.

\section{CONCLUSION}

This study shows that the prevalence of WPV among primary HCW is high and comparable to the prevalence among hospital based HCW. Verbal abuse being the commonest type reported. Majority of the perpetrators are patients' relatives and visitors. The significant risk factors of WPV were gender, age, ethnicity, marital status, district of work, perception of being worried of violence, number of co-workers at time of work and OSC after controlling for other sociodemographic factors, safety climate factors and other work characteristics. Since low safety climate is significantly associated with higher odds of WPV, primary interventions should focus on improving safety climate factors in addition to the existing prevention strategies which focuses more on coping with violence. An integrative approach encompassing individual and organizational level strategies should be adopted in developing in preventing WPV among HCW. The approach should include training and counselling at the individual level. Improvement of physical safety features at the organization as well as increasing emphasis on improving awareness and policies regarding organizational safety climate and its positive role in preventing violence and negative work-health related outcome. Future studies must be conducted using a prospective design, simultaneously evaluating individual types of violence and its potential risk factors. Special attention should be given to organizational characteristics of the workplace that may increase the risk of violence.

\section{REFERENCES}

[1] V. Di Martino and M. Musri, Guidance for the prevention of stress and violence at the workplace. Ministry of Human Resources Malaysia and International Labour Organization, Kuala Lumpur, 2001.

[2] C. Mento et al., "Workplace violence against healthcare professionals: A systematic review," Aggression and Violent Behavior, vol. 51, p. 101381, Mar. 2020, doi: 10.1016/j.avb.2020.101381.

[3] S. A. Al-Maskari, I. S. Al-Busaidi, and M. A. Al-Maskari, "Workplace violence against emergency department nurses in Oman: a cross-sectional multi-institutional study," International Nursing Review, vol. 67, no. 2, pp. 249-257, Jun. 2020, doi: 10.1111/inr.12574.

[4] V. d. Martino, "Workplace violence in the health sector. Country case studies Brazil, Bulgaria, Lebanon, Portugal, South Africa, Thailand and an additional 2002. https://www.who.int/violence_injury_prevention/injury/en/WVsynthesisreport.pdf (accessed Jan 20, 2021)

[5] R. B. Al Anazi, S. M. AlQahtani, A. E. Mohamad, S. M. Hammad, and H. Khleif, "Violence against health-care workers in governmental health facilities in Arar City, Saudi Arabia," The Scientific World Journal, vol. 2020, pp. 1-6, Mar. 2020, doi: $10.1155 / 2020 / 6380281$.

[6] H. Al-Omari, A. Abu Khait, H. Al-Modallal, E. Al-Awabdeh, and S. Hamaideh, "Workplace violence against nurses working in psychiatric hospitals in Jordan," Archives of Psychiatric Nursing, vol. 33, no. 5, pp. 58-62, Oct. 2019, doi: 10.1016/j.apnu.2019.08.002.

[7] J. Liu et al., "Prevalence of workplace violence against healthcare workers: a systematic review and meta-analysis," Occupational and Environmental Medicine, vol. 76, no. 12, pp. 927-937, Dec. 2019, doi: 10.1136/oemed-2019-105849.

[8] A. S. Ishak, M. S. Haque, and S. S. Sadhra, "Needlestick injuries among Malaysian healthcare workers," Occupational Medicine, vol. 69, no. 2, pp. 99-105, Apr. 2019, doi: 10.1093/occmed/kqy129.

[9] P. Ruth, M. Samsiah, H. Hamidah, and L. Santhna, "Workplace violence experienced by nurses in Universiti Kebangsaan Malaysia Medical Centre," Medical and Health, vol. 4, no. 2, pp. 115-121, 2009.

[10] N. Zainal, I. Rasdi, and S. M. Saliluddin, "The risk factors of workplace violence among healthcare workers in public hospital," Malaysian Journal of Medicine and Health Sciences, vol. 14, no. SP2, pp. 120-127, 2018.

[11] K. Al-Sahlawi, F. Atawneh, M. Zahid, A. Shahid, and M. Al-Farrah, "Violence against nurses in hospitals: prevalence and effects," British Journal of Nursing, vol. 12, no. 2, pp. 102-107, Jan. 2003, doi: 10.12968/bjon.2003.12.2.11049.

[12] O. Uzun, "Perceptions and experiences of nurses in Turkey about verbal abuse in clinical settings," Journal of Nursing Scholarship, vol. 35, no. 1, pp. 81-85, 2003.

[13] M. Jiao et al., "Workplace violence against nurses in Chinese hospitals: a cross-sectional survey," BMJ Open, vol. 5, no. 3, pp. e006719-e006719, Mar. 2015, doi: 10.1136/bmjopen-2014-006719.

[14] M. L. F. Jacobsen, "Workplace Violence, Organizational culture, and registered nurses' incident reporting patterns in Acute Hospitals in California," Thesis, The University of San Francisco, 2016.

[15] G. D'Ettorre, M. Mazzotta, V. Pellicani, and A. Vullo, "Preventing and managing workplace violence against healthcare workers in Emergency Departments," Acta Bio Medica: Atenei Parmensis, vol. 89, no. suppl. 4, pp. 28-36, 2018, doi: 10.23750/abm.v89i4-S.7113.

[16] Y.-P. Chang, D.-C. Lee, and H.-H. Wang, "Violence-prevention climate in the turnover intention of nurses experiencing workplace violence and work frustration," Journal of Nursing Management, vol. 26, no. 8, pp. 961-971, Nov. 2018, doi: 10.1111/jonm.12621.

[17] T. J. Tobin, "Organizational determinants of violence in the workplace," Aggression and Violent Behavior, vol. 6, no. 1, pp. 91102, Jan. 2001, doi: 10.1016/S1359-1789(00)00011-2.

[18] B. Beech and P. Leather, "Workplace violence in the health care sector: A review of staff training and integration of training evaluation models," Aggression and Violent Behavior, vol. 11, no. 1, pp. 27-43, Jan. 2006, doi: 10.1016/j.avb.2005.05.004. 
[19] D. Chappell and V. Di Martino, Violence at work. International Labour Organization, Geneva, International Labour Office, 2006.

[20] D. Zohar, "A group-level model of safety climate: Testing the effect of group climate on microaccidents in manufacturing jobs," Journal of Applied Psychology, vol. 85, no. 4, pp. 587-596, 2000, doi: 10.1037/0021-9010.85.4.587.

[21] M. A. Griffin and M. Curcuruto, "Safety climate in organizations," Annual Review of Organizational Psychology and Organizational Behavior, vol. 3, no. 1, pp. 191-212, Mar. 2016, doi: 10.1146/annurev-orgpsych-041015-062414.

[22] K. Broadwater, G. R. Grimes, and D. M. Wiegand, "Evaluation of laser coding particulate composition, health effects, and safety climate at a brewery," Centers for Disease Control and Prevention, National Institute for Occupational Safety and Health, May 2019. doi: 10.26616/NIOSHHHE201700723347.

[23] General Assembly of the World Medical Association, "World medical association declaration of helsinki: ethical principles for medical research involving human subjects," The Journal of the American College of Dentists, vol. 81, no. 3, pp. 14-18, 2014.

[24] A. Ariza-Montes, N. Muniz, M. Montero-Simó, and R. Araque-Padilla, "Workplace bullying among healthcare workers," International Journal of Environmental Research and Public Health, vol. 10, no. 8, pp. 3121-3139, Jul. 2013, doi: 10.3390/ijerph10083121.

[25] P. Kines et al., "Nordic Safety climate questionnaire (NOSACQ-50): A new tool for diagnosing occupational safety climate," International Journal of Industrial Ergonomics, vol. 41, no. 6, pp. 634-646, Nov. 2011, doi: 10.1016/j.ergon.2011.08.004.

[26] W.-Q. Lin et al., "Workplace violence and job performance among community healthcare workers in China: the mediator role of quality of life," International Journal of Environmental Research and Public Health, vol. 12, no. 11, pp. 14872-14886, Nov. 2015, doi: 10.3390/ijerph121114872.

[27] W. Basfr, A. Hamdan, and S. Al-Habib, "Workplace violence against nurses in psychiatric hospital settings: perspectives from Saudi Arabia," Sultan Qaboos University Medical Journal [SQUMJ], vol. 19, no. 1, p. 19, May 2019, doi: 10.18295/squmj.2019.19.01.005.

[28] N. S. Ghareeb, D. A. El-Shafei, and A. M. Eladl, "Workplace violence among healthcare workers during COVID-19 pandemic in a Jordanian governmental hospital: the tip of the iceberg," Environmental Science and Pollution Research, vol. 28, no. 43, pp. 61441-61449, Nov. 2021, doi: 10.1007/s11356-021-15112-w.

[29] Y. Tian, Y. Yue, J. Wang, T. Luo, Y. Li, and J. Zhou, "Workplace violence against hospital healthcare workers in China: a national WeChat-based survey," BMC Public Health, vol. 20, no. 1, p. 582, Dec. 2020, doi: 10.1186/s12889-020-08708-3.

[30] A.-H. El-Gilany, A. El-Wehady, and M. Amr, "Violence against primary health care workers in Al-Hassa, Saudi Arabia," Journal of Interpersonal Violence, vol. 25, no. 4, pp. 716-734, Apr. 2010, doi: 10.1177/0886260509334395.

[31] H. Cui et al., "Under-5-years child mortality due to congenital anomalies," American Journal of Preventive Medicine, vol. 50, no. 5, pp. 663-671, May 2016, doi: 10.1016/j.amepre.2015.12.013.

[32] M. Kitaneh and M. Hamdan, "Workplace violence against physicians and nurses in Palestinian public hospitals: a cross-sectional study," BMC Health Services Research, vol. 12, no. 1, p. 469, Dec. 2012, doi: 10.1186/1472-6963-12-469.

[33] Z. Li et al., "Workplace violence against medical staff of Chinese children's hospitals: a cross-sectional study," PLOS ONE, vol. 12, no. 6, p. e0179373, Jun. 2017, doi: 10.1371/journal.pone.0179373.

[34] S. R. Jafree, "Workplace violence against women nurses working in two public sector hospitals of Lahore, Pakistan," Nursing Outlook, vol. 65, no. 4, pp. 420-427, Jul. 2017, doi: 10.1016/j.outlook.2017.01.008.

[35] C. Palumbo, G. S. Di, S. S. Di, F. Carabellese, A. Valerio, and R. Catanesi, "Evaluation of safety at work in a psychiatric setting: the workplace safety assessment," La Medicina del lavoro, vol. 107, no. 4, pp. 284-292, 2016.

[36] M. Ridenour et al., "Incidence and risk factors of workplace violence on psychiatric staff," Work, vol. 51, no. 1, pp. 19-28, Jun. 2015, doi: 10.3233/WOR-141894

[37] A. R. Folgo and J. D. Iennaco, "Staff perceptions of risk factors for violence and aggression in ambulatory care," Work, vol. 65, no. 2, pp. 435-445, Feb. 2020, doi: 10.3233/WOR-203096.

[38] J. T. Dennerlein et al., "Associations between work-related factors and psychological distress among construction workers," Journal of Occupational \& Environmental Medicine, vol. Publish Ah, Jul. 2021, doi: 10.1097/JOM.0000000000002311.

[39] J. Arnetz, L. E. Hamblin, S. Sudan, and B. Arnetz, "Organizational determinants of workplace violence against hospital workers," Journal of Occupational \& Environmental Medicine, vol. 60, no. 8, pp. 693-699, Aug. 2018, doi: 10.1097/JOM.0000000000001345.

[40] J. E. Arnetz, L. S. Zhdanova, D. Elsouhag, P. Lichtenberg, M. R. Luborsky, and B. B. Arnetz, "Organizational climate determinants of resident safety culture in nursing homes," The Gerontologist, vol. 51, no. 6, pp. 739-749, Dec. 2011, doi: 10.1093/geront/gnr053.

[41] V. Isaak, D. Vashdi, D. Bar-Noy, H. Kostisky, S. Hirschmann, and A. Grinshpoon, "Enhancing the safety climate and reducing violence against staff in closed hospital wards," Workplace Health \& Safety, vol. 65, no. 9, pp. 409-416, Sep. 2017, doi: $10.1177 / 2165079916672478$.

[42] L.-Q. Yang, P. E. Spector, C.-H. (Daisy) Chang, M. Gallant-Roman, and J. Powell, "Psychosocial precursors and physical consequences of workplace violence towards nurses: A longitudinal examination with naturally occurring groups in hospital settings," International Journal of Nursing Studies, vol. 49, no. 9, pp. 1091-1102, Sep. 2012, doi: 10.1016/j.ijnurstu.2012.03.006.

[43] X. Zhou, S. F. Rasool, and D. Ma, "The relationship between Workplace Violence and Innovative Work Behavior: The Mediating Roles of Employee Wellbeing," Healthcare, vol. 8, no. 3, p. 332, Sep. 2020, doi: 10.3390/healthcare8030332.

\section{BIOGRAPHIES OF AUTHORS}

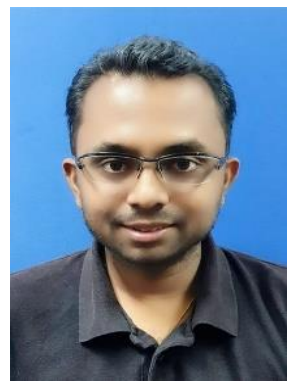

Sudeash Rajakrishnan (D) $8 \mathrm{SC}$ S is a senior medical officer in the Petaling District Health office Ministry of Health Malaysia. He is currently pursuing Doctoral degree in public health in Faculty of Medicine University Malaya. Dr. Sudeash received a Bachelor's degree in Medicine from Manipal University India, a Master of Business Administration degree from the Malaysian Technology University (UTM) and a Master of Public Health from the faculty of Medicine University Malaya. His research focuses on Workplace violence among healthcare workers and infectious disease outbreak management. He can be contacted at email: sudeash27@gmail.com. 


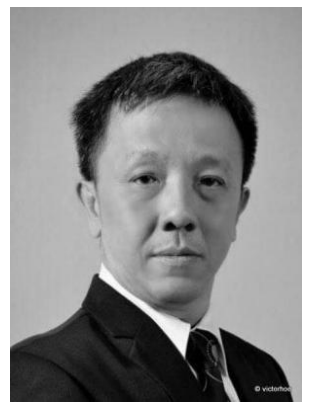

Victor Hoe Chee Wai Abdullah (D) SC S P is a Professor of Occupational and Public Health. He heads the Academic Section in the Department of Social and Preventive Medicine, Faculty of Medicine in the University of Malaya and the Occupational Health, Safety and Environmental Unit in University Malaya Medical Centre. He started his career as an academic in 2004 when he joins the Department. His passion is in the use of technology to enhance and simplify work. He has been experimenting in various forms of online teaching and assessment since 2012. During the COVID-19 pandemic he was part of the team that transform the 8-weeks Community Posting programme for the undergraduate medical programme from a field posting to an online posting. The core of the programme of appreciating the diversity of medicine and public health was maintain through innovative approaches. He holds a Doctor of Philosophy in Occupational Health and Safety from Monash University in Melbourne Australia. He also has the Master of Public Health, Master of Public Health (Occupational Health) and Master of Engineering (Safety, Health and Environment) from the University of Malaya, and the Master of Occupational Safety and Health from the University of Turin and the International Labour Organization (ILO) - International Training Centre in Turin, Italy. He is a Fellow of the Academy of Medicine Malaysia and Fellow of the Academy of Occupational and Environmental Medicine Malaysia. He was the recipient of the first of the two International Commission for Occupational Health (ICOH) and ILO Master Fellowship. He can be contacted at victorhoe@um.edu.my

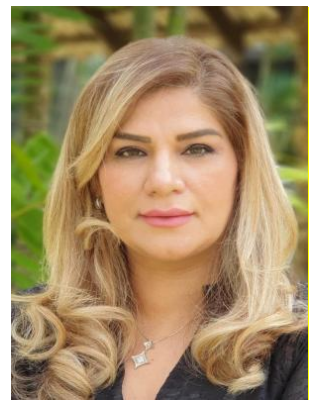

Nasrin Aghamohammadi (D) SI SC P is a Professor of Enviromental and Public Health Her core expertise is in Environmental Health Engineering, Climate Change Adaptation, Urban Heat Island Phenomenon and Health Impact. Since 1995 she has targeted towards contamination measurement and possible control. She has an extensive background in pure and applied research as well as engineering background in Graduate faculty of Environment, University of Tehran and Chemical Engineering, University of Malaya. She has acquired, applied and has taken pride in a very wide range of experiences and activities from hands-on projects such as projects involving air, water, wastewater, solid waste and related health issues. She led as the Principal Investigator for various local and international research focusing on urban health and climate change addressing Sustainable Development Goals 3, 11 and 13 targeting future cities. Currently, she is Heading the Centre for Occupational and Environmental Health and also heading the Environmental Unit, OSHE, UMMC. She can be contacted at nasrin@um.edu.my. 